\title{
The Tibetan Uterotonic Zhi Byed 11: Mechanisms of Action, Efficacy, and Historical Use for Postpartum Hemorrhage
}

\author{
Rebecca Lynn Coelius, ${ }^{1}$ Amy Stenson, ${ }^{2}$ Jessica L. Morris, ${ }^{3}$ \\ Mingji Cuomu, ${ }^{4,5}$ Carrie Tudor, ${ }^{6}$ and Suellen Miller ${ }^{7,8,9}$ \\ ${ }^{1}$ School of Medicine, University of California, San Francisco, 50 Beale Street, Suite 1200, San Francisco, CA 94105, USA \\ ${ }^{2}$ Department of Obstetrics and Gynecology, David Geffen School of Medicine, Center for the Health Sciences, University of California, \\ Los Angeles, 10,833 Le Conte Avenue, Los Angeles, CA 90095, USA \\ ${ }^{3}$ Safe Motherhood Program, University of California, San Francisco, 50 Beale Street, Suite 1200, San Francisco, CA 94105, USA \\ ${ }^{4}$ The Institute for Social and Cultural Anthropology, University of Oxford, 386 London Road, Headington, Oxford OX3 8DW, UK \\ ${ }^{5}$ Tibetan Medical College, Lhasa, Tibet 850000, China \\ ${ }^{6}$ School of Nursing, The Johns Hopkins University, 525 N. Wolfe Street, Baltimore, MD 21205, USA \\ ${ }^{7}$ Department of Obstetrics, Gynecology, and Reproductive Sciences, University of California, San Francisco, 50 Beale Street, Suite 1200, \\ San Francisco, CA 94105, USA \\ ${ }^{8}$ Safe Motherhood Programs, Bixby Center for Global Reproductive Health, School of Medicine, University of California, San Francisco, \\ 50 Beale Street, Suite 1200, San Francisco, CA 94105, USA \\ ${ }^{9}$ Maternal Child Health Program, School of Public Health, University of California, Berkeley, Berkeley, CA 94720, USA
}

Correspondence should be addressed to Rebecca Lynn Coelius, rlmitchell1@gmail.com

Received 9 February 2011; Revised 12 April 2011; Accepted 25 May 2011

Academic Editor: Raffaele Capasso

Copyright ( 2012 Rebecca Lynn Coelius et al. This is an open access article distributed under the Creative Commons Attribution License, which permits unrestricted use, distribution, and reproduction in any medium, provided the original work is properly cited.

\begin{abstract}
Objective. To explore evidence for the traditional Tibetan medicine, Zhi Byed 11 (ZB11), for use as a uterotonic. Methods. The eleven ingredients in ZB11 were chemically analyzed by mass spectroscopy. A review was conducted of Western allopathic literature for scientific studies on ZB11's individual components. Literature from Tibetan and other traditional paradigms were reviewed. Results. Potential mechanisms of action for ZB11 as a uterotonic include laxative effects, a dose-dependant increase in smooth muscle tissue peristalsis that may also affect the uterus smooth muscle, and chemical components that are prostaglandin precursors and/or increase prostaglandin synthesis. A recent RCT demonstrated comparable efficacy to misoprostol in reducing severe postpartum hemorrhage $(\mathrm{PPH})(>1000 \mathrm{~mL})$ and greater effect than placebo. Historical and anecdotal evidence for ZB11 and its ingredients for childbirth provide further support. Discussion. ZB11 and its ingredients are candidates for potentially effective uterotonics, especially in low-resource settings. Further research is warranted to understand the mechanisms of action and synergy between ingredients.
\end{abstract}

\section{Introduction}

1.1. Uterotonics for Prevention of Postpartum Hemorrhage $(P P H) . P P H$ is a leading cause of maternal morbidity and mortality worldwide. It is estimated that of the approximately 350,000 women who die annually from complications of pregnancy and childbirth, more than $25 \%$ die of obstetric hemorrhage [1]. This burden is unequally held by developing countries, where it occurs at a rate 100 times higher than in the developed world [2]. One key factor is that many women deliver at home without skilled delivery attendance, where complications often go unrecognized and untreated. By the time a problem is identified and the woman is transported to an appropriate facility, it may be too late. Women can deteriorate so rapidly that even if they arrive at an appropriate medical facility alive, they may already be in irreversible shock and/or have developed disseminated intravascular coagulopathy (DIC) [3].

The third stage of labor is the time period between the birth of the infant and delivery of the placenta and 
membranes. Failure or delay of the uterus to appropriately contract after delivery can lead to rapid and massive hemorrhage. Shortening the third stage of labor and ensuring that the uterus is well contracted during this time has the potential to decrease blood loss and the incidence of hemorrhage. The World Health Organization (WHO), the International Federation of Gynecology and Obstetrics (FIGO), and the International Confederation of Midwives (ICM) advocate the use of a uterotonic to decrease postpartum bleeding by up to $50 \%-70 \%$ [4].

A uterotonic is a substance that increases the tone (causes contraction) of the uterus, an organ composed of smooth muscle tissue. In both allopathic and traditional and herbal medicine, substances that are called uterotonics often have laxative, purgative, diarrheagenic, cathartic, abortifacient, and emmenagoguic effects. Some uterotonics are biochemically synthesized hormones, such as oxytocin, that act on distant hormone receptors or upstream from other hormones in the body to induce uterine contractions. Others may be synthetic prostaglandins or prostaglandin precursors. Prostaglandins are lipid compounds derived enzymatically from fatty acids and serve as locally acting messenger molecules performing important functions in the body such as regulating the contraction and relaxation of smooth muscle [5].

Since 2007, the WHO PPH Prevention Guidelines have stated that the uterotonic of choice for prophylaxis of $\mathrm{PPH}$ is $10 \mathrm{IU}$ of oxytocin delivered intramuscularly [6]. Oxytocin (pitocin and syntocinon) is a hormone produced in the hypothalamus that plays a critical role in labor and delivery by stimulating uterine contraction, and in lactation by causing milk letdown. However, there are barriers to its use in low-resource settings. To maintain the highest potency, oxytocin requires refrigeration. It is only effective if given parenterally [4], thus safe administration of oxytocin requires staff trained in intravenous or intramuscular administration techniques, sterile needles, and safe disposal for injection equipment. These are frequently unavailable or too costly during births in low-resource settings. The uterotonic ergometrine has similar efficacy to oxytocin but has more side effects, which makes it the preferred option only when oxytocin is not available [6]. Like oxytocin, its utility in lowresource settings is lessened by special storage requirements and parenteral administration [7].

The uterotonic misoprostol has been recommended as an alternative to oxytocin and ergometrine for the prevention of $\mathrm{PPH}$ in low-resource settings, primarily due to its greater ease of administration and storage [8]. Misoprostol (Cytotec) is a synthetic prostaglandin E1 analogue that has been shown to significantly decrease PPH when compared to placebo [9, 10]. Unlike oxytocin, misoprostol can be taken orally and is also relatively stable; it can be stored at room temperature in a closed container safe from humidity with a shelf life of several years [11].

Misoprostol has drawbacks, most notably side effects including pyrexia, nausea, shivering, and diarrhea. Studies of $600 \mathrm{mcg}$ of misoprostol have shown pyrexia and shivering to be most common, with $4 \%-38 \%$ reporting pyrexia and $32 \%-57 \%$ reporting shivering $[7,9,10]$. These findings are dose dependant; malignant hyperpyrexia has been reported at $800 \mathrm{mcg}$ orally $[10,12]$, with potentially dangerous outcomes such as uterine rupture, abruption, fetal demise, and maternal death if used inappropriately during the active phase of labor at doses above $50 \mathrm{mcg}[13,14]$. Another barrier is that misoprostol is not approved for obstetric or gynecologic indications in many countries [15], and thus may not be widely available. Where use is restricted because of concerns for its use as an abortifacient, it may only be found on the black market, causing concern for its purity and safety. Due to misoprostol's side effects and inconsistent outcomes across studies [16], the search for an alternative oral uterotonic for low-resource settings continues.

The ideal uterotonic for prevention of $\mathrm{PPH}$ at the home or community level is one that is simultaneously efficacious, affordable, widely available, does not require electricity or technology for effective storage, has a low side effect profile and high safety level, and is compatible with local beliefs and traditional practices. There may be alternatives to current allopathic medicines within traditional medical systems that would fit these ideals for the prevention of $\mathrm{PPH}$.

Since at least $1500 \mathrm{BC}$ traditional medical practices have taken advantage of the uterotonic properties of local herbs to promote uterine contractions and/or control PPH. These systems include but are not limited to US-based midwifery, African traditional, Ayruveda, Chinese traditional, and Tibetan medicine. The history of ergometrine is an example of how a naturally occurring substance was discovered to be a uterotonic and became widely used in Western allopathic medicine. Ergometrine is derived from the naturally occurring substance ergot, the alkaloid-containing product of the fungus, Claviceps purpurea, which grows on grain. References to ergot date as far back as $600 \mathrm{BC}$, and its effects on pregnancy were identified in the 16 th century by midwives who noted an increased rate of miscarriage during epidemics of "ergotism", a disease caused by eating contaminated rye bread [17]. In 1935, the active substance was identified and named ergometrine, effectively initiating the modern era of allopathic uterotonics $[18,19]$.

In the USA, Chumash Native American communities in California have used Trichostema lanatum and lanceolatum leaves in a decoction to pass the afterbirth (placenta) [20]. Midwives frequently use herbal preparations that are purported to increase uterine tone (red raspberry leaf), act as an emmenagogue to provoke menstruation (penny royal), or induce labor contractions (blue cohosh, black cohosh, and castor oil) [21]. Among South African native populations, the Xhosa, Zulu, and Sotho tribes use over 57 traditional herbal medicines during pregnancy and childbirth [22], which have exhibited direct smooth muscle activity on the uterus and/or ileum in vitro [23]. In Ayurvedic medicine, the gentle anthraquinone-containing laxative Aragvadha, Cassia fistula-Fructus, is used in pregnancy to stop bleeding and cause a general "downward" movement. Rhubarb root is administered internally to treat many forms of hemorrhage [24]. In traditional Chinese medicine, (TCM), Motherwort, or Leonurus heterophyllus sweet is considered the key ingredient for $\mathrm{PPH}$ prescriptions and has been developed into 
an injection for clinical use (personal communication with Taxiang Wu, Chinese Cochrane Centre, December 10, 2009).

In the Tibetan Autonomous Region (TAR) of China, Zhi Byed 11 (ZB11) has been the traditional treatment of choice for PPH for over 700 years and continues to be widely used by Tibetan traditional healers and providers. It is also prescribed to aid and quicken delivery, increase uterine contractions, deliver the placenta, and to manage other complications of pregnancy such as hypertension and infection. Currently, much cheaper than conventional uterotonics at USD 0.04 per dose, ZB11 is also widely available in the TAR and has a high degree of acceptability. Taken orally and not requiring any special storage, ZB11 is practical for home and community births. ZB11 seems to hold none of the barriers allopathic uterotonics such as oxytocin, ergometrine, and misoprostol do for use in the TAR, and continues to be used by Tibetan traditional healers [25].

Phuntsog Wangmo, a traditional Tibetan healer, and the cultural director and an instructor at the Shang Shung Institute of America, International Institute for Tibetan Studies, Conway, Mass, USA, shares her personal experience using ZB11 in contemporary rural Tibet:

"Zhi Byed 11, we use this commonly, this is a very good medicine, it helps to clean the uterus, for example, it helps if something remains in the uterus to make sure that it is expelled. When I am working with someone in labor, I do several things. I will try to make sure that the baby's head is down.... We give some nutrition (like warm broth) if the person is strong enough. If contractions are getting weak, or the patient does not dilate, we give $\mathrm{ZB} 11$. We give one pill orally. If nothing happens after 1.5 hours, we can give another one. We are allowed to give 2-3 pills. Once the baby has come out, we give warm oil treatment. We keep the mother warm and give her nutritional food, warm broth or soup. At the same time, we get the placenta, put oil on the abdomen, and do gentle massage, downward traction on placenta. If the placenta does not come out or if some pieces remain inside, we would give another ZB11. We watch the bleeding, if it continues, we check the color of the blood. If dark, we are not so worried, if it is fresh, then we are worried. I worked in a remote area, so I have to stay with them at their house. If needed, I stay overnight. If I have to leave, then I give a good dosage of Gur gum 8 and make sure no bleeding. I leave them with 3-5 pills of ZB11, and have them take 1 in the morning for three days. The reason for this is to clean the uterus and keep it healthy. I think it works as a team between all the ingredients. The contractions become stronger, more painful when it is given. I use it in almost everyone, but the amount varies, between 1 pill or many pills. I was always able to get that medicine, the ingredients are not that difficult to find. It is not expensive and there are many good sources."

Traditional Tibetan medical literature states that ZB11 owes both its efficacy for preventing and treating $\mathrm{PPH}$, and low rate of side effects, to a careful balance of eleven synergistic natural ingredients (see Figure 1). Recently, ZB11 became the first traditional uterotonic to be rigorously tested against an allopathic uterotonic for PPH. In a double-blind, randomized, controlled trial (RCT) conducted by Miller et al. [25] in three maternity hospitals in Lhasa, TAR, delivering women $(n=967)$ were randomly assigned to receive either ZB11 or misoprostol [25].

As herbal products can differ depending what part of the ingredient is used, the ratios, and the quality of the ingredients, the Miller et al. [25] study used a single large batch of ZB11 made at a local factory, the the Mentzikhang Traditional Tibetan Medicine Factory, in Lhasa, Tibet in May 2004. Employing only one factory and using one single batch for the entirety of the study minimized this risk. Samples of the study's ZB11 product were retested for potency every six months throughout the trial from August 2005 to March 2007 to confirm there was no degradation.

The study's primary combined outcome, which included incidence of PPH (blood loss $\geq 500 \mathrm{~mL}$ ) administration of open label uterotonics, or maternal death, was found to be lower among the misoprostol group (16.1\% versus $21.8 \%$ for ZB11; $P=0.02)$. The proportion of women who experienced blood loss $\geq 500 \mathrm{~mL}$ was also lower with misoprostol $(12 \%$ versus $17 \% \mathrm{ZB} 11$ ). However, there were no significant differences in the more clinically important indicators of $\mathrm{PPH}$ : blood loss $\geq 1000 \mathrm{~mL}$, (2.1\%, misoprostol versus $3.1 \%$, ZB11, $P=0.29$ ), mean measured blood loss $(304 \mathrm{~mL}$ for misoprostol versus $332 \mathrm{~mL}$ for $\mathrm{ZB11}, P=0.15)$ or median measured blood loss $(250 \mathrm{~mL}$ versus $265 \mathrm{~mL}$ for ZB11, $P=$ 0.086). The length of the third stage of labor was also similar (7.2 min for misoprostol versus $6.9 \mathrm{~min}$ for ZB11). Use of additional uterotonics occurred in $16 \%$ of those given ZB11 and $13 \%$ of those given misoprostol. Side effects were more common in the misoprostol group, with fever significantly more common in the misoprostol group $(2.7 \%$ versus $0.8 \%$, $P=0.03)$. There were no maternal deaths in either arm of the study [25].

ZB11's comparable results for several outcomes, long history of use and acceptability in the TAR, strong anecdotal support from Tibetan healers, low side effect profile, and the pressing need to find a uterotonic appropriate for use in lowresource settings prompted us to take a more detailed examination of ZB11. We were specifically interested in ZB11's individual ingredients and any known synergistic effects between ingredients for possible mechanisms of action as a uterotonic, their toxicology and safety profile in clinical use, and historical and current uses, especially for purposes related to childbirth.

\section{Methods}

In this paper, we explore the potential mechanisms of action for ZB11 as a uterotonic, either as a combined preparation 


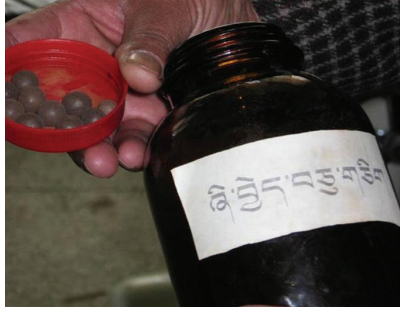

ZB11

Finished preparation

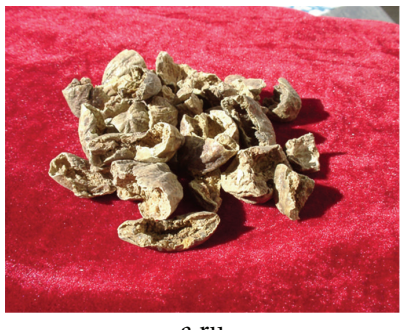

a ru

(Terminalla chehula Retz) fruit with one seed $75 \mathrm{~g}$

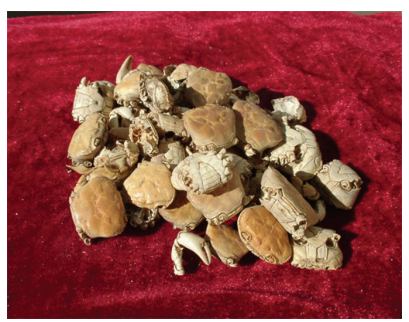

dig srin

(Potamon yuanense kemp) flesh $25 \mathrm{~g}$

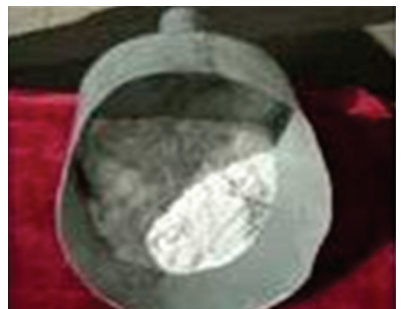

bul tog

(Trona)

mineral $150 \mathrm{~g}$

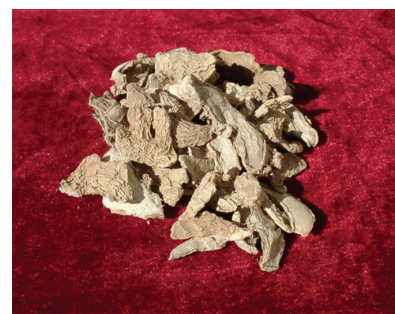

sga kya (Zingiber officinale Rose; Hedychium spicatum) root $50 \mathrm{~g}$

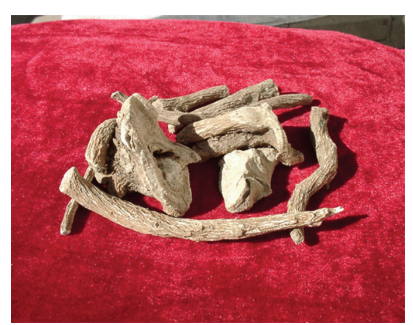

ma nu (Inula racemosa

Hood; Inula helenium L) root $25 \mathrm{~g}$

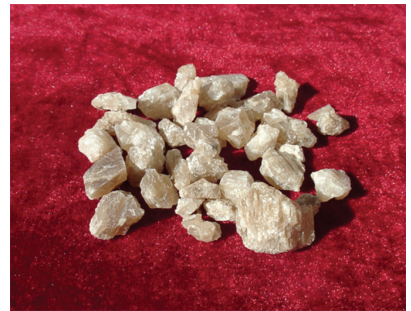

cong zhi

(calcitum varieties)

mineral $125 \mathrm{~g}$

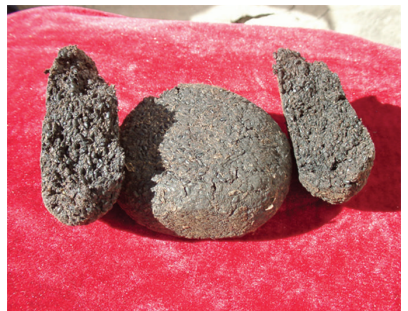

star bu

(Hippophae rhamnoides L) fruit with one seed $35 \mathrm{~g}$

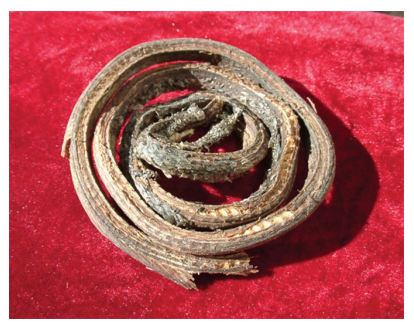

sbrul sha

(Zaocys dhumnades Cantor) flesh $20 \mathrm{~g}$

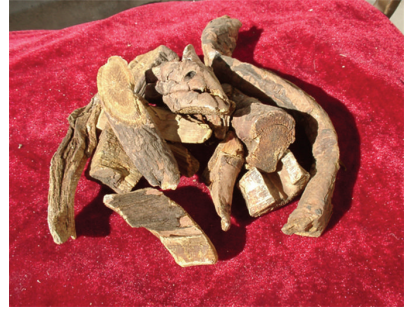

lcum rtsa

(Rheum palmatum L) root $100 \mathrm{~g}$

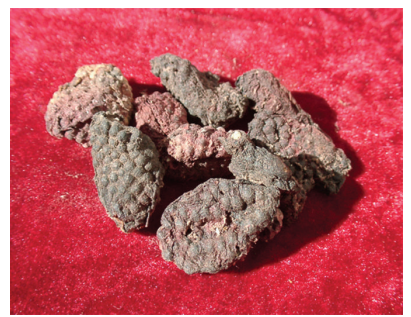

ol mo'se (Sinopodophyllum hexandrum Royle)

fruit with many seeds $35 \mathrm{~g}$

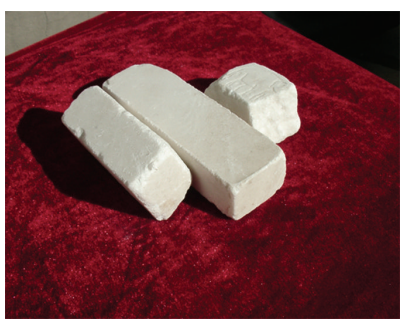

rgya tsha

(Sal ammoniacum) mineral $15 \mathrm{~g}$

Figure 1: Zhi Byed 11 ingredients by name, component, and weight.

or as a subset of its individual ingredients. The methodology of this paper makes use of chemical analysis, evidence-based review of both Western allopathic literature and peer reviewed journals on traditional and herbal medicine, and a review of Tibetan and other traditional and herbal medicine paradigms.

The chemical makeup of the ZB11 used in the Miller et al. [25] study was examined by mass spectroscopy at the University of Utah Center for Human Toxicology [27]. These findings were then cross-checked against those reported for each ingredient in Mosby's Handbook of Herbs and Natural Supplements [28].

A literature search was conducted for each of ZB11's eleven ingredients. Databases used included PubMed, the Cochrane Database of Systematic Reviews, and the CENTRAL Controlled Trials Database. No parameters were set for year, as many herbal medicines have a long history and historical accounts may be considered valuable. The terms entered were both the Latin name and the common name of the individual ingredients found in ZB11. Articles in English or those translated into English were examined.
We reviewed articles and selected those with relevance to potential mechanisms of action on smooth muscle (as the uterus is made up of smooth muscle), pregnancy, bleeding, or uterotonic function. All animal and/or human studies that used the pure ingredients were included. Information about side effects and toxicity was also collected from this search. The historical usage of ZB11 as a complex preparation of eleven ingredients and of each individual ingredient was explored by a review of texts on Tibetan traditional medicine, traditional Chinese medicine, and herbal medicine.

\section{Results}

3.1. Chemical Analysis. The ZB11 used in the Miller et al. [25] study was examined by mass spectrometry by Andrenyhak [27], University of Utah Center for Human Toxicology. This paper was created to test the ZB11 product to be used in the Miller et al. [25] study. The primary compounds identified included long chain fatty acids, long chain fatty alcohols, and long chain methyl esters, 
TABLe 1: Zhi Byed 11 Tibetan, Latin, and common names, chemical components.

\begin{tabular}{llll}
\hline Tibetan name & Latin name & Common name & Chemical component [25, 26] \\
\hline a ru & Terminalia chehula retz & Chebulic myrobalan & Ellagic acid, gallic acid, lufeoic acid, and chebulinic acid \\
\hline bul tog & Trona & sodium, bicarbonate & $\mathrm{NaHCO}_{3}$ \\
\hline cong zhi & Calcitum & calcium & Calcium \\
\hline lcum rtsa & Rheum Palmatum L & $\begin{array}{l}\text { Chinese, Turkish, or East } \\
\text { Indian rhubarb }\end{array}$ & $\begin{array}{l}\text { Anthraquinones: rhein, chrysophanol, aloe } \\
\text { emodintannins gallo, galloy-1glucose stilbene, } \\
\text { phenolic, and polyketide synthase sennosides }\end{array}$ \\
\hline ma nu & $\begin{array}{l}\text { Inula Racemosa Hood, } \\
\text { Inula Helenium }\end{array}$ & elecampane & $\begin{array}{l}\text { Volatile oil: alantolactone lactone: Alantol } \\
\text { polysaccharides: lnulin }\end{array}$ \\
\hline ol mo'se & $\begin{array}{l}\text { Sinopodophyllum } \\
\text { hexandrum (Royle) }\end{array}$ & $\begin{array}{l}\text { Himalayan or Chinese } \\
\text { mayapple }\end{array}$ & $\begin{array}{l}\text { Podophyllotoxin Picropodophyllin: Apha and beta } \\
\text { phyllin }\end{array}$ \\
\hline rgya tsha & Sal ammoniacum & salt of sulphur/tar & Na, S \\
\hline sbrul sha & Zaocys dhumnades Cantor & black snake meat & Not found \\
\hline sdig srin & Potamon ynnanense kemp & freshwater crab shell & Not found \\
\hline sga skya & $\begin{array}{l}\text { Zingiber offficinale Rose, } \\
\text { Hedychium Spicatum Ham }\end{array}$ & ginger, ginger Lily & $\begin{array}{l}\text { Pungent gingerol, zingerone, Shogaol volatile oil, } \\
\text { bisabolene, zingiberene, zingiberol, and Sesquiterpene }\end{array}$ \\
\hline star bu & Hippophae rhamnoides L & sea buckhorn & $\begin{array}{l}\text { Anthranoid, emodin, anthraquinone glycosides, } \\
\text { frangulin A, B, glucofrangulin A, B }\end{array}$ \\
\hline
\end{tabular}

TABLe 2: Potential mechanisms of action of Zhi Byed 11.

\begin{tabular}{ll}
\hline $\begin{array}{l}\text { Tibetan } \\
\text { name }^{\mathrm{a}}\end{array}$ & Mechanism of action \\
\hline $\begin{array}{l}\text { lcum } \\
\text { rtsa }\end{array}$ & $\begin{array}{l}\text { Anthranoids: laxative due to direct colon irritation, } \\
\text { purgative potentially due to abnormal expression of } \\
\text { aquaporins [27]. } \\
\text { Emodins: dose-dependant smooth muscle contraction }\end{array}$ \\
& $\begin{array}{l}\text { [28] due to increased concentration of calcium in } \\
\text { smooth muscle and the activation of calcium chloride } \\
\text { channels via enhancement of membrane Gi/Go protein } \\
\text { signal transducer pathway [29]. CaCl } 2 \text { can reverse } \\
\text { effects. Heightens effects of Acetylcholine [28]. }\end{array}$ \\
& $\begin{array}{l}\text { Sennosides: animal studies demonstrate intestinal } \\
\text { peristalsis due to depolarization of cell membranes, } \\
\text { quickened burst slow wave potential, and increased } \\
\text { frequency of spike potentials [30]. }\end{array}$ \\
\hline ma nu & $\begin{array}{l}\text { Highly potent tracheal and ileal smooth muscle } \\
\text { relaxant in animal studies [30]. }\end{array}$ \\
\hline sga skya & $\begin{array}{l}\text { Decreases nausea and vomiting [31] and prokinetic } \\
\text { activity in digestive system of animal models due to } \\
\text { effects on muscarinic M3 receptors of stomach fundus } \\
\text { [32]. }\end{array}$ \\
\hline star bu & $\begin{array}{l}\text { Anthranoids: Laxative due to direct colon irritation } \\
\text { [19]. }\end{array}$ \\
\hline
\end{tabular}

${ }^{a}$ Studies on sbrul sha, ol mo'se, rgya tsha, a ru, bul tog, cong zhi, and sdig srin are not found.

such as Eudesma (5,11 (13)-diene-8,12-olide), Physcion, and Chrysophanol (9,10-Anthracenedione, 1,8-dihydroxy-3methyl) (see Table 1) [27].

3.2. Review of Western Allopathic Literature. Both RCTs and animal models were found for four of the ZB11 ingredients which suggested possible mechanisms of action for lcum rtsa, star bu, and sga skya as uterotonics (see Table 2). These include the laxative effects of anthranoids, smooth muscle contractions of emodins (dose dependent), the peristaltic effect of sennosides on the gastrointestinal system, and the prokinetic and drug potentiating activity of sga skya (due to its inhibition of first pass hepatic degradation). While no studies looked specifically at the uterus for mechanism of action, the effects on smooth muscle and the GI system is relevant, since the uterus is also made up of smooth muscle. Thus, often these mechanisms affect multiple organs with smooth muscle and similar receptors, as evidenced by some of the side effects experienced by the GI system when allopathic uterotonics are used. Sga skya's potentiating mechanism would make any ingredient processed by the liver more potent and/or act longer though we were not able to find studies documenting whether the liver is responsible for the metabolism and excretion of other ZB11 ingredients. Conversely, ma nu was found to have smooth muscle relaxant activity on the ileum and trachea; there was no study documenting its effect on uterine smooth muscle.

Typical use of ZB11 is a short course (1-3 days) at relatively low doses (1-3 pills.) In the Miller et al. [25] study, all side effects, including diarrhea, shivering, and fever, were more common in the misoprostol group than the ZB11 group, with fever being significantly higher (2.7\% misoprostol versus $0.8 \% \mathrm{ZB} 11, P=0.03$ ). While this is a statistically significant result, clinically, it may not be considered relevant. Shivering was the most common side effect, occurring in $12 \%$ of participants given ZB11 and $16 \%$ of participants given misoprostol. There were no life threatening adverse events reported for ZB11 in this trial [25].

Other studies also describe side effects associated with some ZB11 ingredients (see Table 3). It is important to note that outside the Miller et al. [25] study, these reported side effects were not accompanied by specific dosage levels or schedules. The most serious side effects were reported only anecdotally with unquantified long-term use or high doses 
TABLe 3: Zhi Byed 11 ingredient side effects and toxicities.

\begin{tabular}{|c|c|c|}
\hline $\begin{array}{l}\text { Tibetan } \\
\text { name }^{\mathrm{a}}\end{array}$ & Common side effects and toxicities $[32,33]$ & $\begin{array}{l}\text { Side effects and toxicities in large doses/prolonged use }{ }^{b} \\
\text { [33] }\end{array}$ \\
\hline cong zhi & $\begin{array}{l}\text { Constipation, anorexia, nausea, vomiting, flatulence, } \\
\text { diarrhea, and rebound hyperacidity }\end{array}$ & None found \\
\hline lcum rtsa & Cramp like discomforts & None found \\
\hline ma nu & $\begin{array}{l}\text { Irritate mucus membranes, sensitizing, and can cause } \\
\text { allergic contact dermatitis by forming haptens }\end{array}$ & Vomiting, diarrhea, cramps, and symptoms of paralysis \\
\hline ol mo’se & Nausea, vomiting, diarrhea, and abdominal pain & $\begin{array}{l}\text { Seizures, stupor, coma, hepatotoxicity, leukopenia, } \\
\text { thrombocytopenia, anemia, and apnea }\end{array}$ \\
\hline sga skya & Nausea, vomiting, anorexia, and hypersensitivity reactions & Arrhythmias \\
\hline star bu & $\begin{array}{l}\text { Nausea, vomiting, diarrhea, anorexia, abdominal cramps, } \\
\text { hepatotoxicity, dehydration, and nervousness/tremors }\end{array}$ & None found \\
\hline
\end{tabular}

TABle 4: Uses of Zhi Byed 11 Individual Ingredients in Traditional Tibetan Medicine.

\begin{tabular}{|c|c|}
\hline a ru & $\begin{array}{l}\text { Laxative [34], improves and gives positive body } \\
\text { energy, helpful for most diseases. }\end{array}$ \\
\hline bul tog & $\begin{array}{l}\text { Laxative, synergy with lcum rtsa; downward } \\
\text { expelling [34] }\end{array}$ \\
\hline cong zhi & $\begin{array}{l}\text { Prevents vomiting, treats constipation [35] } \\
\text { balances bul tog by absorbing carbonic acids } \\
\text { [34]; treats diarrhea caused by either virus or } \\
\text { indigestion; supports "bon" nutrition; helpful } \\
\text { for treating fever from the endocrine system } \\
\text { and for treating ulcers [36] }\end{array}$ \\
\hline lcum rtsa & Treats irregular menstruation [33] \\
\hline ma nu & $\begin{array}{l}\text { Induces sweat and treats fever [36]; downward } \\
\text { expelling functions [33] }\end{array}$ \\
\hline ol mo'se & $\begin{array}{l}\text { Thins coagulated blood, promotes normal } \\
\text { menses; promotes uterine contractions, } \\
\text { delivers baby, expels placenta, some consider } \\
\text { the most important ingredient in } Z B 11 \text { [33]. } \\
\text { Also used to cleanse other uterine disorders } \\
\text { [36] }\end{array}$ \\
\hline rgya tsha & $\begin{array}{l}\text { Promotes uterine contractions, dilates cervix } \\
\text { [33]; used to cleanse the whole body, ease urine } \\
\text { retention, and reduce wound infections }\end{array}$ \\
\hline sbrul sha & $\begin{array}{l}\text { Delivers baby, expels placenta [33]; and } \\
\text { dissolves clots [37] }\end{array}$ \\
\hline sdig srin & $\begin{array}{l}\text { Downward circulation, prevents cramping, } \\
\text { promotes uterine contractions, dilates cervix } \\
\text { [33]; eases urine retention and is useful for } \\
\text { various kidney disorder [37] }\end{array}$ \\
\hline sga skya & $\begin{array}{l}\text { Improves blood circulation and congestion, } \\
\text { prevents clots [33] }\end{array}$ \\
\hline star bu & $\begin{array}{l}\text { Downward expelling of blood, prevents blood } \\
\text { clots [34]; cools down fevers and provides pain } \\
\text { relief, prevents blood clots (mostly used for } \\
\text { women's disorders or lung problems) [33] }\end{array}$ \\
\hline
\end{tabular}

and were not reported in any controlled trials or animal models. [25, 33].

3.3. Review of Traditional and Herbal Medicine Literature. There was strong historical and anecdotal evidence for the use of ZB11 ingredients, not only in Tibetan medicine (see Table 4) but also in other traditional medicines (see Table 5), as diuretics, uterine, and other smooth muscle stimulants, laxatives, and for side-effect management such as preventing and treating nausea and vomiting in a range of disorders.

\section{Discussion}

Our analysis supports ZB11's safety and effectiveness as a uterotonic with the potential to decrease the risk of $\mathrm{PPH}$, particularly in low-resource settings, where current allopathic uterotonics face significant barriers to use. ZB11 has several qualities that make it an attractive uterotonic for prevention and/or treatment of $\mathrm{PPH}$ at the home or community level in Tibet. With over 700 years of history, it is widely culturally accepted by birthing women, Tibetan healers, and family members in Tibet. At the same time, it is highly affordable (USD 0.04 per dose) widely available, does not require electricity or technology for effective storage, and requires minimal training for administration. Its safety profile is similar to misoprostol, the current standard of care. In places where access to a steady supply of "Western" medication may be limited, this offers an important, less costly alternative.

Several possible mechanisms of action were identified for ZB11 as an uterotonic. These include a dose-dependant increase in peristalsis of smooth muscle, which is the uterus tissue type. Fatty acid esters, such as the linoleic acid, methyl ester, and oleic acid methyl ester found in the mass spectrometry solution of ZB11, are prostaglandin precursors and are involved in prostaglandin synthesis $[45,46]$. Eudesma, or Inula helenium, contains alantolactone, which is known to have cathartic, or purgative properties (emmenagoguic, secretagogue, secretolytic) [47]. 9,10-Anthracenedione, 1,8dihydroxy-3-methyl (also known as chrysophanol) and rhein are both anthroquinones found in Chinese rhubarb species, such as Rheum palmatum. Researchers at the Beijing Medical University's College of Pharmacology have conducted studies on the chemical composition and bioactivities of dozens of Rheum species and attribute many with purgative properties. Rhein and chrysophanol are also found in the senna species, known as a laxative $[25,33]$. 
TABLE 5: Relevant therapeutic uses of Zhi Byed 11 ingredients in other traditional systems.

\begin{tabular}{|c|c|c|}
\hline $\begin{array}{l}\text { Tibetan name* } \\
\text { (common name) }\end{array}$ & Tradition/region of use & Relevant therapeutic use within system/region \\
\hline a ru Chebulic Myrobalan & Ayurvedic/Indian & $\begin{array}{l}\text { Improving gastrointestinal motility, laxative, purgative, } \\
\text { and cure for bleeding }[38,39]\end{array}$ \\
\hline $\begin{array}{l}\text { bul tog Sodium, } \\
\text { bicarbonate }\end{array}$ & Africa Herbal & Laxative $[40]$ \\
\hline \multirow[t]{2}{*}{ lcum rtsa rhubarb } & $\begin{array}{l}\text { Traditional Chinese } \\
\text { Medicine }\end{array}$ & Purgative, laxative [41]; to treat hemorrhage $[30,32]$ \\
\hline & Ayurvedic & To treat hemorrhage $[19,21]$ \\
\hline $\begin{array}{l}\text { ol mo'se Himalayan } \\
\text { mayapple }\end{array}$ & $\begin{array}{l}\text { Traditional Chinese } \\
\text { Medicine }\end{array}$ & $\begin{array}{l}\text { Emmenagogue, uterine stimulant, and abortifacient } \\
\text { [42] }\end{array}$ \\
\hline \multirow[t]{4}{*}{ sga skya ginger } & $\begin{array}{l}\text { Traditional Chinese } \\
\text { Medicine }\end{array}$ & $\begin{array}{l}\text { Increases gastric secretions, increases intestinal } \\
\text { peristalsis [33] }\end{array}$ \\
\hline & Ayurvedic & $\begin{array}{l}\text { Treating constipation, nonspecific antispasmodic effect } \\
\text { on smooth muscles }[35,43]\end{array}$ \\
\hline & $\begin{array}{l}\text { Unani (Indian Traditional } \\
\text { Greco-Arabic medicine) }\end{array}$ & Laxative [35] \\
\hline & $\begin{array}{l}\text { East African Herbal } \\
\text { (Uganda) }\end{array}$ & Induction of uterine contractions [19] \\
\hline star bu sea buckthorn & $\begin{array}{l}\text { Traditional Asian Medicine } \\
\text { (Mongolia and China) }\end{array}$ & Constipation gynecological diseases [44] \\
\hline
\end{tabular}

* Information not found for cong zhi, ma nu, rgya tsha, sbrul sha or sdig srin.

In the Miller et al. [25] study, the sample size was calculated using the assumption that the effect of ZB11 would not be the same as placebo but would be at least a $10 \%$ decrease from hemorrhage occurrence when no treatment was given. This assumption was validated in the study, where there was a $15 \%$ decrease in $\mathrm{PPH}$ rates from baseline (before the initiation of any treatment.) This 15\% decrease further supports the uterotonic effect of ZB11. Notably, in the same study, there was no significant difference between misoprostol and ZB11 in blood loss $\geq 1000 \mathrm{~mL}$. This is striking given that blood loss $\geq 1000 \mathrm{~mL}$ is considered one of the most clinically meaningful indices of $\mathrm{PPH}$, correlating with the 95th percentile for blood loss and greater associated morbidity and mortality [48]. An uncomplicated vaginal delivery often results in blood loss greater than $500 \mathrm{~mL}$. A change in systolic blood pressure is not seen until $1000 \mathrm{~mL}$ is lost, and a blood loss of greater than $2000 \mathrm{~mL}$ is necessary before systolic blood pressure reaches levels as low as $50-70 \mathrm{~mm} \mathrm{Hg}$ [49]. More research is warranted to determine the true effect of ZB11 in preventing and/or treating PPH. Given that a placebo-controlled trial is unlikely due to ethical challenges, the best option may be a double-blinded noninferiority trial of ZB11 versus misoprostol, with the main outcome evaluating the effect on severe hemorrhage (blood loss $>1000 \mathrm{~mL}$ ). We also recommend that any future RCT follow the CONSORT statement for herbal medicine RCTs [50].

Traditional Tibetan medicine is crafted for each patient depending on many specific environmental and individual factors. Scientifically, this is difficult to evaluate using a "Western" approach. Similar to dosing trials in the pharmaceutical industry, different dosages and/or combinations of ZB11 ingredients may alter the efficacy and/or side effects of the medication. Evaluating different combinations of all
11 ingredients would require a large amount of resources and time and still may not result in a "one size fits all" pill. Therefore, capturing the true effect of ZB11 via standardized scientific "Western" analysis may always be difficult. It may be useful to conduct more qualitative work surrounding the traditional proportions of ingredients that make up ZB11 and test a wide range of samples to identify the most common mixture though a challenge is that traditionally a mixture is made specific to each patient. It may also be beneficial to compare different formulations of ZB11 looking for a balance of efficacy and safety before beginning a trial.

The reported side effects in the Miller et al. [25] study of diarrhea, shivering, and fever were lower for ZB11 than with oral misoprostol though the clinical significance of the difference is unclear. If a medication has a high side-effect profile, medical personnel may be reluctant to administer the medication; women themselves may refuse to receive it in subsequent deliveries or may tell friends and family to avoid the medication and/or the facility where it is administered. Several of the ingredients in ZB11 are known in Tibetan Medicine to prevent the most common side effects that typically result from administration of prostaglandins, and were seen at lower rates with ZB11 than with misoprostol in the Miller et al. [25] trial. For example, cong zhi is used to prevent and/or treat gastrointestinal side effects; $m a n u$ prevents fever, sdig srin prevents cramping, and $a r u$ is generally believed to increase body energy and prevent a host of sideeffects $[33,34,37]$. It may be that the lower side effect profile of ZB11 is due to these balancing effects although this has not yet been critically analyzed.

Historical and anecdotal evidence for ZB11 and its ingredients' clinical utility provides further support for ZB11's potential efficacy. What is especially interesting to note is 
that some of ZB11's ingredients are used for similar purposes across very different healing traditions. In African herbal medicine, bul tog (calcium bicarbonate) is a well-known laxative [40], while in Western Uganda, Sga skya, (Zingiber officinale rose) is used to induce contractions [22]. Ol mo'se (Himalayan mayapple) is used in traditional Chinese medicine as a strong uterine stijmulant [26]. Rhubarb derivatives, such as lcum rtsa, also appear in systems as diverse as traditional Chinese and Aryuvedic medicine to treat hemorrhage $[21,42]$. The use of similar ingredients to augment labor and cause uterine contractions in diverse traditional medical practices lends support to the probability of an uterotonic effect. While one explanation may be that these healing traditions stem from similar ancestry and heritage, the persistence of these compounds still suggests that they have been found in practice to be effective by healers over many generations. Evaluation of these compounds and others within traditional medicine has the potential to identify culturally relevant, effective regimens that may prevent morbidity and mortality from obstetric hemorrhage.

A limitation of our study was that we only looked at three databases, none of which were Chinese (such as Chinese National Knowledge Infrastructure and Wan Fang) due to language barriers). We were also only able to review papers that were written in or translated to English. Thus, studies may be missing from our analysis. Moving forward, we recommend that the database sources be broadened, and that additional Tibetan healers be consulted for their personal opinions on and experience with ZB11.

\section{Conclusions}

Progress in Western medicine has often been the result of accidental discovery, creating synthetic versions of naturally occurring plant and animal substances, or adaptations of a traditional medical system's preparations. Examples include the uterotonic ergometrine's derivation from the fungus Claviceps purpurea, and the use of the ancient Chinese Traditional medication, Qinghao (Artemisia annua) for the modern treatment of malaria. The findings of this ZB11 review suggest potential for both allopathic and continued traditional use of $\mathrm{ZB} 11$ as an uterotonic, with further research warranted to understand the underlying mechanisms of action and synergy between ingredients.

\section{Conflict of Interests}

None of the authors has any conflict of interests to disclose.

\section{Acknowledgments}

The authers would like to acknowledge the Oxytocin Initiative at PATH, the Bill and Melinda Gates Foundation, and the NIH BIRCWH (building interdisciplinary careers in women's health).

\section{References}

[1] WHO, The World Health Report 2005: Make Every Mother and Child Count, World Health Organization, Geneva, Switzerland, 2005.

[2] K. S. Khan, D. Wojdyla, L. Say, A. M. Gülmezoglu, and P. F. Van Look, "WHO analysis of causes of maternal death: a systematic review," The Lancet, vol. 367, no. 9516, pp. 1066-1074, 2006.

[3] S. Miller, J. M. Turan, K. Dau et al., "Use of the non-pneumatic anti-shock garment (NASG) to reduce blood loss and time to recovery from shock for women with obstetric haemorrhage in Egypt," Global Public Health, vol. 2, no. 2, pp. 110-124, 2007.

[4] ICM/FIGO, "Joint Statement: Prevention and Treatment of Post-partum Haemorrhage," New Advances for Low Resource Settings; 2006.

[5] R. J. Nelson, An Introduction to Behavioral Endocrinology, Sinauer Associates, Sunderlans, Mass, USA, 3rd edition, 2005.

[6] WHO, "Recommendations for the Prevention of Postpartum Haemorrhage," 2007, http://www.who.int/making_pregnancy_safer/publications/WHORecommendationsforPPHaemorrhage.pdf.

[7] G. Walraven, "Misoprostol for prevention of postpartum hemorrhage in home deliveries in rural Gambia: an interim report on a randomized control trial," in XVII FIGO World Congress of Gynecology and Obstetrics, FIGO World Congress of Gynecology and Obstetrics, Santiago, Chile, November 2003.

[8] A. M. Gülmezoglu, F. Forna, J. Villar, and G. J. Hofmeyr, "Prostaglandins for preventing postpartum haemorrhage," Cochrane Database of Systematic Reviews, no. 3, Article ID CD000494, 2007.

[9] R. J. Derman, B. S. Kodkany, S. S. Goudar et al., "Oral misoprostol in preventing postpartum haemorrhage in resourcepoor communities: a randomised controlled trial," The Lancet, vol. 368, no. 9543, pp. 1248-1253, 2006.

[10] G. J. Hofmeyr, G. Walraven, A. M. Gülmezoglu, B. Maholwana, Z. Alfirevic, and J. Villar, "Misoprostol to treat postpartum haemorrhage: a systematic review," BJOG, vol. 112, no. 5, pp. 547-553, 2005.

[11] D. Toledo-Velasquez, H. T. Gaud, and K. A. Connors, "Misoprostol dehydration kinetics in aqueous solution in the presence of hydroxypropyl methylcellulose," Journal of Pharmaceutical Sciences, vol. 81, no. 2, pp. 145-148, 1992.

[12] D. Flandermeyer, C. Stanton, and D. Armbruster, "Uterotonic use at home births in low-income countries: a literature review," International Journal of Gynecology and Obstetrics, vol. 108, no. 3, pp. 269-275, 2010.

[13] A. E. Diab, "Uterine ruptures in Yemen," Saudi Medical Journal, vol. 26, no. 2, pp. 264-269, 2005.

[14] H. A. Mousa and Z. Alfirevic, "Treatment for primary postpartum haemorrhage," Cochrane Database of Systematic Reviews, no. 1, Article ID CD003249, 2007.

[15] Gynuity Health Projects, "Map of Misoprostol Approval," 2009, http://gynuity.org/resources/info/map-of-misoprostolapproval/.

[16] WHO, "Unedited Draft report of the 17th Expert Committee on the Selection and use of Essential Medicines (Version 30)," Unedited WHO Technical Report Series 2009, May 2009, http://www.who.int/selection_medicines/committees/expert/ 17/WEBuneditedTRS_2009.pdf.

[17] D. R. Elbourne, W. J. Prendiville, G. Carroli, J. Wood, and S. McDonald, "Prophylactic use of oxytocin in the third stage of labour," Cochrane Database of Systematic Reviews, no. 4, Article ID CD001808, 2001. 
[18] T. F. Baskett, "The development of oxytocic drugs in the management of postpartum haemorrhage," The Ulster Medical Journal, supplement, pp. 2-6, 2004.

[19] C. De Costa, "St Anthony's fire and living ligatures: a short history of ergometrine," The Lancet, vol. 359, no. 9319, pp. 1768-1770, 2002.

[20] J. D. Adams and C. Garcia, "Women's health among the chumash," Evidence-Based Complementary and Alternative Medicine, vol. 3, no. 1, pp. 125-131, 2006.

[21] C. Belew, "Herbs and the childbearing woman: guidelines for midwives," Journal of Nurse-Midwifery, vol. 44, no. 3, pp. 231252, 1999.

[22] D. J. H. Veale, K. I. Furman, and D. W. Oliver, "South African traditional herbal medicines used during pregnancy and childbirth," Journal of Ethnopharmacology, vol. 36, no. 3, pp. 185-191, 1992.

[23] T. L. Kaido, D. J. H. Veale, I. Havlik, and D. B. K. Rama, "Preliminary screening of plants used in South Africa as traditional herbal remedies during pregnancy and labour," Journal of Ethnopharmacology, vol. 55, no. 3, pp. 185-191, 1997.

[24] S. Pole, Ayurvedic Medicine, The Principles of Traditional Practice, Elsevier, 2006.

[25] S. Miller, C. Tudor, V. Thorsten et al., "Randomized double masked trial of Zhi Byed 11, a Tibetan traditional medicine, versus misoprostol to prevent postpartum hemorrhage in Lhasa, Tibet," Journal of Midwifery and Women's Health, vol. 54, no. 2, pp. 133-141, 2009.

[26] The Zhejiang College of Traditional Chinese Medicine, A Handbook of Traditional Chinese Gynecology, Blue Poppy Press, Zehjiang, China, 1987.

[27] D. Andrenyhak, "Solid material sample; analysis consultant case CC-20-03," Letter: University of Utah Center for Human Toxicology, July 2003.

[28] L. Skidmore-Roth, Mosbys Handbook of Herbs and Natural Supplements, 4th edition, 2009.

[29] F. Li, S. C. Wang, X. Wang et al., "Novel exploration of cathartic pharmacology induced by rhubarb," Zhongguo Zhong Yao Za Zhi, vol. 33, no. 4, pp. 481-484, 2008.

[30] Z. H. Jin, D. L. Ma, and X. Z. Lin, "Study on effect of emodin on the isolated intestinal smooth muscle of guinea-pigs," Zhongguo Zhong Xi Yi Jie He Za Zhi, vol. 14, no. 7, pp. 429$431,1994$.

[31] W. X. Yang, Z. G. Jin, W. S. Xu, Z. S. Tian, and S. D. Guo, "Effects of sennosides on cellular electric activities in smooth muscle cells of guinea pig taenia coli," Zhongguo Yao Li Xue Bao, vol. 14 , no. 5, pp. 430-432, 1993.

[32] M. Reiter and W. Brandt, "Relaxant effects on tracheal and ileal smooth muscles of the guinea pig," Arzneimittel-Forschung, vol. 35, no. 1A, pp. 408-414, 1985.

[33] M. N. Ghayur, A. H. Khan, and A. H. Gilani, "Ginger facilitates cholinergic activity possibly due to blockade of muscarinic autoreceptors in rat stomach fundus," Pakistan Journal of Pharmaceutical Sciences, vol. 20, no. 3, pp. 231-235, 2007.

[34] V. Bhagwan Dash, Formulary of Tibetan Medicine, Classics India Publications, New Delhi, India, 1998.

[35] Tillotson Institute. Rhubarb Root (Rheum palmatum), 2009, http://oneearthherbs.squarespace.com/important-herbs/rhubarb-root-rheum-palmatum.html.

[36] M. Tshomo, Knowledge of pregnancy and delivery and obstetrical diseases and treatments from a Tibetan medical perspective, dissertation, Tibtan Medical College, Lhasa, Canada, 2004.

[37] B. Blumenthal, G. Goldberg, K. Hall et al., The Complete German Commission E Monographs: Therapeutic Guide to
Herbal Medicines, The American Botanical Council, Austin, Tex, USA, 1998.

[38] M. Cuomu, The Cultural Understanding of Obstetrics and the Treatment for Various Diseases' (Tibetan: Monad Pha Pai Nad La Gso Bcos Byas Pa'i Nyams Yig'), TAR Central Publishing, 2009.

[39] T. J. Tsarong, Handbook of Traditional Tibetan Drugs, Their Nomenclature, Composition, Use, and Dosage, Tibetan Medical Publications, 1986.

[40] B. D. Miglani, P. Sen, and R. K. Sanyal, "Purgative action of an oil obtained from Terminalia chebula," The Indian journal of medical research, vol. 59, no. 2, pp. 281-283, 1971.

[41] M. D. Tamhane, S. P. Thorat, N. N. Rege, and S. A. Dahanukar, "Effect of oral administration of terminalia chebula on gastric emptying: an experimental study," Journal of Postgraduate Medicine, vol. 43, no. 1, pp. 12-13, 1997.

[42] D. Garry, R. Figueroa, J. Guillaume, and V. Cucco, "Use of castor oil in pregnancies at term," Alternative Therapies in Health and Medicine, vol. 6, no. 1, pp. 77-79, 2000.

[43] J. Elzea Kogel, N. Trivedi, J. Barker, and S. Krukowsk, Industrial Minerals \& Rocks: Commodities, Markets, and Uses, Society for Mining Metallurgy \& Exploration, 7th edition, 2006.

[44] "Ayurvedic Herbal Information About Ginger: Its Origins, Properties, Usage and Health Benefits," 2009, http://www. ayurvera.com/Ayurveda08-Ayurvedic-Herbal-Guide-to-Herbsand-Ingredients/Ayurvedicherbal-guide-to-herbs-treatments$\% 27 \mathrm{G} \% 27 /$ Ginger.htm.

[45] NIIR, Compendium of Medicinal Plants, National Institute of Industrial Research, New Delhi, India, 2005.

[46] Natural Standard Monograph, "Sea buckthorn (Hippophae rhamnoides)," 2010, http://naturalstandard.com/index-abstractasp?create-abstract=seabuckthornasp\&title=Sea\%20buckthorn.

[47] J. S. Pendergraft, W. F. O’Brien, and M. C. Williams, "Modulators of prostaglandin E2 synthesis in human amnion," Journal of the Society for Gynecologic Investigation, vol. 1, no. 2, pp. 131-134, 1994.

[48] R. Creasy, R. Resnik, J. Iams, C. Lockwood, and T. Moore, Creasy and Resnik's Maternal-Fetal Medicine: Principles and Practice, Saunders, 6th edition, 2008.

[49] ACOG Educational Bulletin, "Hemorrhagic shock. Number 235, April 1997 (replaces no. 82, December 1984). American College of Obstetricians and Gynecologists," International Journal of Gynecology \& Obstetrics, vol. 57, no. 2, pp. 219-226, 1997.

[50] J. J. Gagnier, H. Boon, P. Rochon, D. Moher, J. Barnes, and C. Bombardier, "Reporting randomized, controlled trials of herbal interventions: an elaborated CONSORT statement," Annals of Internal Medicine, vol. 144, no. 5, pp. 364-367, 2006. 


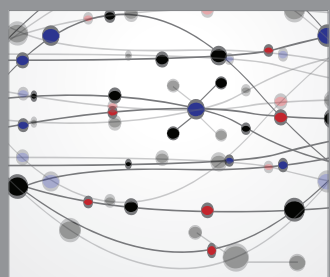

The Scientific World Journal
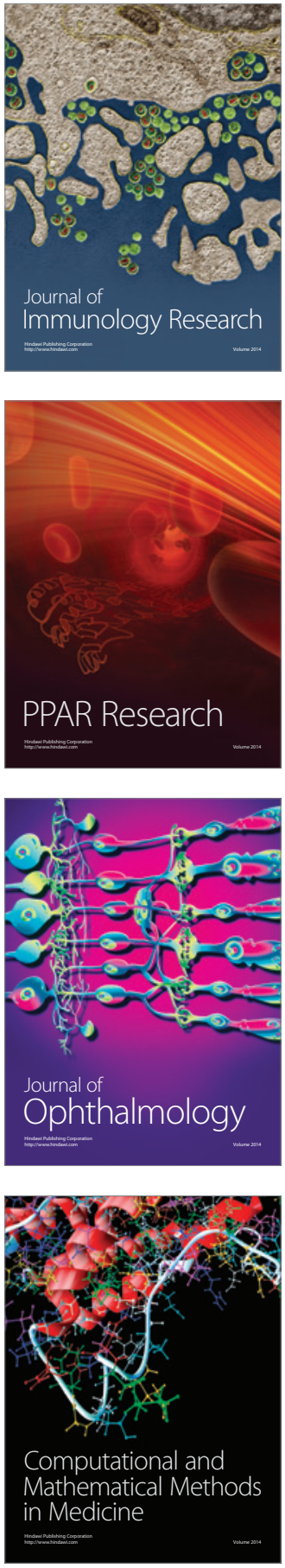

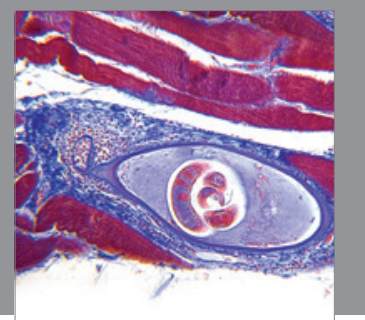

Gastroenterology

Research and Practice
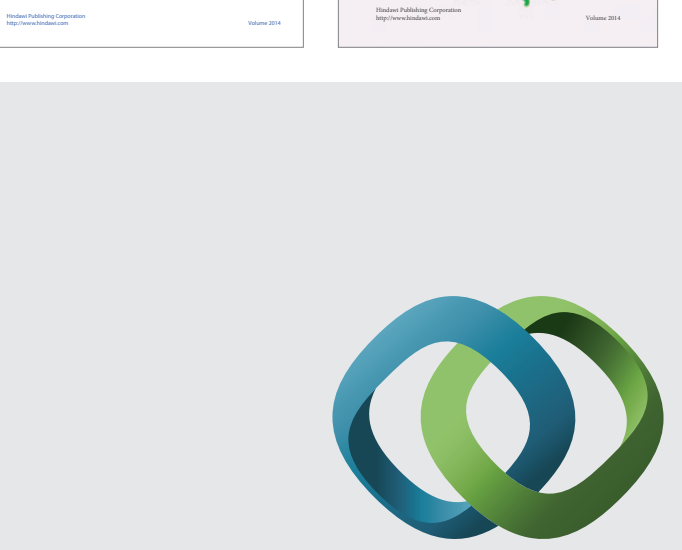

\section{Hindawi}

Submit your manuscripts at

http://www.hindawi.com
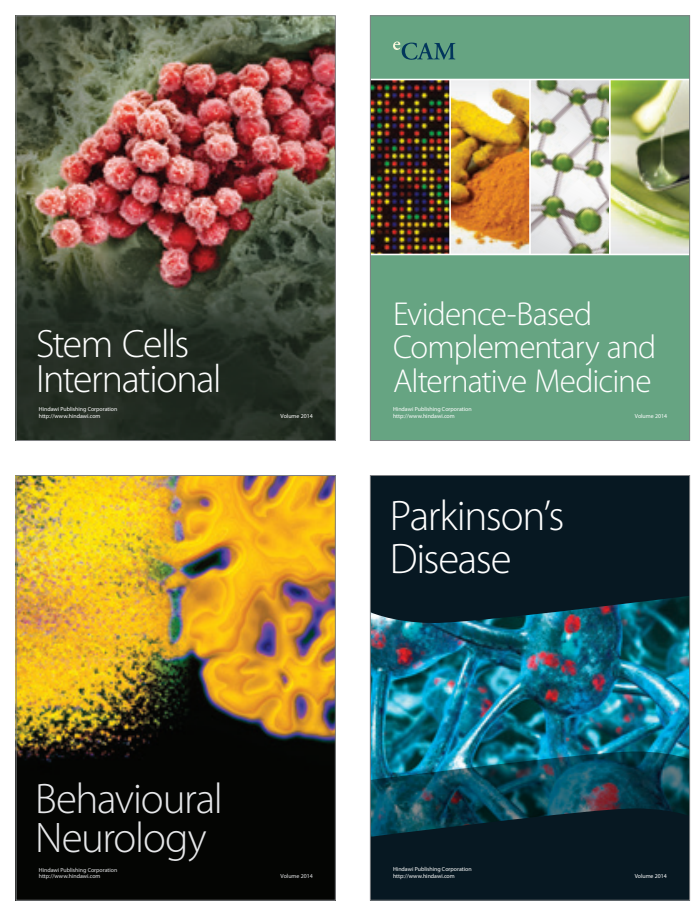

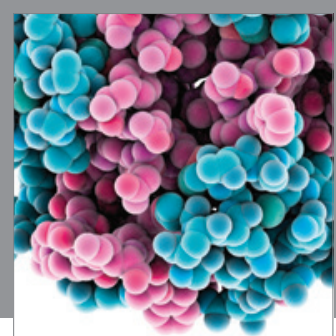

Journal of
Diabetes Research

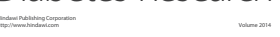

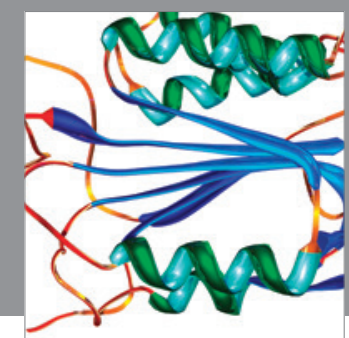

Disease Markers
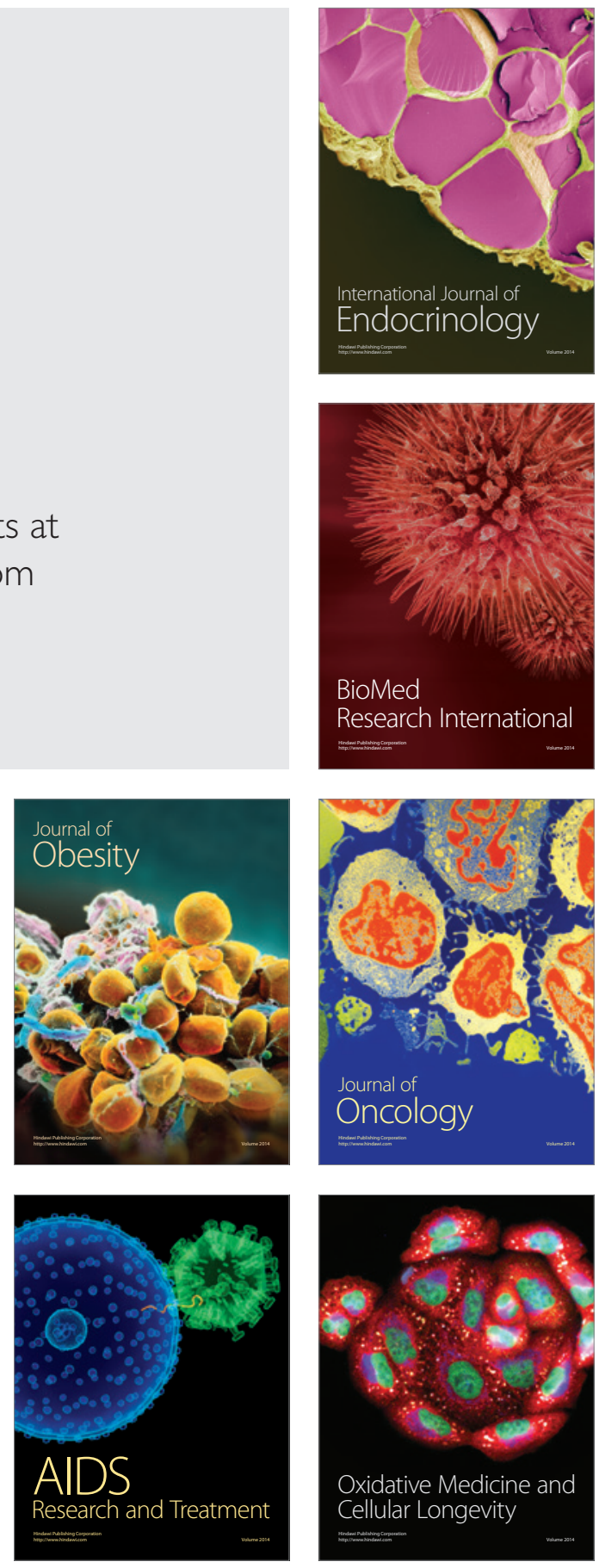